\title{
A review of collective protective measures for workers in contaminated sites
}

\author{
A. Ledda, S. Berardi \& E. Bemporad \\ Department of Production Plants and Human Settlements, \\ Italian Workers' Compensation Authority (INAIL), Italy
}

\begin{abstract}
The industrialization of an ever-growing number of productive processes has caused a greater spread of potentially hazardous chemical substances. Their management becomes a critical issue especially in case of accident or inadequate operations potentially causing a soil and/or groundwater contamination. Thus the importance of measures to mitigate health risks to workers in these cases is growing. The aim of the work is to describe the most widespread collective measures used to protect the health of workers exposed through inhalation of indoor or outdoor air contaminated by pollutants present in saturated and unsaturated soil. The case of workplaces similar to life places (such as offices, markets, hospitals, schools or banks) where the use of Personal Protective Equipment (PPE) could not be appropriate will be addressed. The collective protection measures described are divided in active and passive systems as well as managerial decisions. The variables governing the measure selection, cleanup operations, the working environment, the site geology and hydrogeology, the type of building (new or existing) and its characteristics, will be illustrated. Selecting the most suitable measure allow to improve the efficacy of the operation itself thus better protecting every worker in the contaminated site, not only the ones directly involved in remediation activities.

Keywords: collective protective measures, workplaces, workers' safety, vapour intrusion, soil contamination.
\end{abstract}

\section{Introduction}

Contamination by chemicals is emerging as a potential concern at many sites across the industrialized nations. This study summarizes the latest available information and methods to protect every worker involved in site remediation. 
The focus is on selected treatment, site remediation technologies and related issues. The aim is not to provide detailed engineering information or protocols, nor to provide lists of vendors. Rather, it is intended that the reader will be in general informed to make correct selections of collective measures in workplaces (and any building type such as residential, commercial or industrial one). The mitigation systems dealt with in this review are primarily engineered "direct" mitigation techniques for vapour intrusion both active and passive, such as sealing of entry routes, depressurization, venting, or installation of membrane barriers. Most of inhalation cases occur when contaminants from either the groundwater or soil enter the soil gas at the water table or in the unsaturated zone. The contaminants then migrate under the influence of convective flow or diffusion until they exit into the atmosphere or enter the zone of influence of a building (ITRC [1]).

\section{Indoor inhalation}

Strategies for indoor inhalation mitigating involve both active and passive techniques. Active mitigation strategies typically require a continuous consumption of energy. In most cases, an active system is based on a negative pressure gradient underneath a structure, compensating and going over the house depressurization generated by the environment (the primary driving force for vapour intrusion). Alternative active measures may be based on overpressure inside (or nearby) the workplace or removing or diluting vapours after they have entered the building. The last two approaches require a removal rate greater than the contaminant entry rate. Passive mitigation strategies, usually require no or very low consumption of energy and are indicated when the vapour intrusion problem is less severe. The efficiency range of passive systems is variable from 30 to 90 percent (USEPA [2]). These performance results were mostly obtained by short term monitoring. In many cases, the performance of passive systems may vary significantly due to seasons or to weather-related factors.

\subsection{Active mitigation systems}

Active systems are usually the most used for their greater efficiency and speed to clean air polluted by vapour intrusion.

\subsubsection{Sub Slab Depressurization}

The most frequently used active mitigation systems [3] use the Sub Slab Depressurization (SSD), a technique developed for radon mitigation. This system consists of one or more fans (or blowers) that extract air/soil-gas from under the slab (creating a depressurization field) beneath a building, induce the flow of vapours to one or more collection points and vent it to the atmosphere through a series of discharge pipes. In buildings without slabs this technique is also known as active soil depressurization (ASD) (USEPA [4]). The average soil/building depressurization should be in the range 4-10 Pascal. The SSD uses one or more extraction points in the slab or perforated ventilation pipes that run beneath the 
slab and direct the vapours to a centrally located plenum sub-slab box connected to vertical riser piping. The fan usually is installed outside or inside the extraction point in the slab or in an empty attic above the top of the roof, at a location that ensures that the exhaust will not be drawn back into the building through windows or openings. If the fan is installed inside the extraction point in the slab all the cracks or conjunctions in the pipes must be carefully sealed to prevent infiltration of soil gas inside the building. More than $99.5 \%$ concentration reductions (NJDEP [5]) have been obtained in carefully installed and designed systems. The SSD is installed commonly in civil and commercial buildings.

\subsubsection{Sub Membrane Depressurization}

In buildings with dirt (earthen, gravel, etc.) floor basements or crawlspaces typically Sub Membrane Depressurization (SMD) systems are used. These techniques are similar to Sub Slab ones with the exceptions that an impermeable generally high-density polyethylene (HDPE), membrane, is used instead of a concrete slab and that the extraction points are installed vertically through the membrane. Similarly to the case of SSD, care should be taken to ensure that the membranes are completely sealed to the perimeter walls, piers or membrane seams to optimize the efficiency of the system. A wearing surface is also recommended to protect the membrane receiving workers foot traffic. The SMD is installed frequently in industrial and commercial buildings.

\subsubsection{Block Wall Depressurization}

Another system to protect workplaces using the negative pressure is the Block Wall Depressurization (BWD); crawlspace ventilation by BWD is sometime considered to be a variation of SSD system. This technique depressurizes the void spaces within the block wall by drawing soil-gas/air from inside to outside the wall. The BWD is used in buildings with hollow block walls especially if the outside surfaces are in contact with the soil and are not adequately cleaned. In this case the usual sub-slab suction point may not adequately mitigate infiltration of soil gas inside the wall cavities. This method is often combined with one of the other depressurization techniques. It is often difficult to effectively seal the cracks and gaps in existing buildings foundation walls, especially block walls, and therefore it may be difficult to depressurize the entire foundation wall. Furthermore, uniform depressurization of block walls can be problematic and may cause basement depressurization enhancing vapour intrusion (or backdrafting of fireplaces and combustion appliances), so this technique is recommended only when depressurization proves to be inadequate to control intrusion. The BWD is installed mainly in residential and commercial buildings (USEPA [2]).

\subsubsection{Sub Slab Pressurization}

In some situations the fan can be oriented so that it blows into the sub-slab area creating a Sub Slab Pressurization (SSP). The positive pressure below the slab creates a barrier, preventing vapour intrusion. SSP is normally used when the permeability of the soil is too high to generate a sufficient pressure for SSD and 
effective sub-slab ventilation is not feasible. Otherwise in low-permeability soils this technique is comparable with SSD, but it needs more energy consumption. Block wall pressurization (BWP) can be used to increase SSP where the permeability of the sub-slab material is too high to efficiently depressurize. The SSP is easy to install mostly in new buildings.

\subsubsection{Adjustments to building heating, ventilation and air conditioning}

Adjustment to building Heating, Ventilation and Air Conditioning (HVAC) systems to produce positive indoor/outdoor pressure differences, is an alternative system to Pressurization/Depressurization techniques. This system needs to run continuously HVAC system fan and regular maintenance and air balancing of the system is needed for system efficiency. In some existing buildings, modifying the HVAC system may be too complicated to effectively mitigate the vapour intrusion pathway. The older constructions, however, do not often exhibit the required air sealing to make this system cost effective. In addition, some buildings do not have forced air systems (e.g. hot water circulation systems with radiators). Typically this technique is applied to commercial structures but may not be appropriate with high concentrations of contaminants in the soil gas.

\subsubsection{Increasing air exchange rate/ventilation}

Methods based only on increasing air exchange rate/ventilation with fan or HVAC in the workplace without pressurization can achieve only 50-75 percent of reduction in concentrations. Further increase in ventilation rate usually become uncomfortable for occupants due to air speed (CIRIA [6]). For this reason this technique is installed mainly in industrial and commercial buildings and may be acceptable in temporarily used areas (MassDEP [7]). Directly cleaning air in the structure, by adsorption and filtration poses an alternative to whole-building depressurization or pressurization when these methods are not feasible (e.g. wet soils). These systems typically use various processes including zeolite, activated carbon adsorption, ozone oxidation and photo-catalytic oxidation. Note, however, that technologies based on ozone generation are not recommended because ozone may cause adverse health effects (e.g. the US State of California has banned the sale of residential ozone producing air cleaners in 2009 (CalEPA [8, 9])). Mitigation methods that employ adsorption materials, such as activated carbon, generate anyway waste to be regenerated or properly disposed of.

\subsection{Passive mitigation systems}

Passive systems use natural phenomena, passive barrier, thermal effects, pressure gradients and wind to stop vapour intrusion and/or to develop suction in the stack. Passive measures may be an alternative to active systems when the subsurface contaminant concentrations are low, but these systems are not generally as efficient and fast as active systems. For these reasons they should not be used to mitigate imminent or acute hazards. However the effectiveness of passive mitigation approach may be confirmed through an adequate number of indoor-air sampling. 


\subsubsection{Sealing of the building envelope}

An important component of any mitigation strategy is the sealing of the building envelope. All vapour entryways (such as cracks in the subsurface walls or slab, openings in the slab, utility penetrations, floor drains, elevators, HVAC and electrical conduits and other related pathways) should be sealed to prevent infiltration of soil gas. This technique usually is not a stand-alone mitigation measure, however it will enhance the effectiveness of every type of mitigation measure, and will enable pressurization/depressurization systems to maintain adequate pressure differential. Sealing materials must:

- have good adherence to building materials,

- be durable and water/temperature resistant,

- be workable at the installation temperature,

- have high elasticity and compressibility,

- have good recovery after stretching or compression, not shrink after curing,

- have low or no emissions of hazardous VOCs.

A closed-cell polyurethane foam or other inert gas-impermeable material is recommended for utility conduits penetrating the slab. In many cases, the evaluation of cracks and gaps in foundation floor slabs and walls is impracticable in existing building (e.g. in finished basements tile, wood or carpeted floors and walls prohibit a complete inspection). Therefore, diagnostic testing should be conducted prior to, and after installation. Care should be taken to ensure that there are no pollutant sources inside the workplace.

\subsubsection{Passive barriers}

Passive barriers are techniques using spray-applied materials, sheet membranes or structures installed below a building to eliminate the vapour intrusion pathway. Some studies have demonstrated that it is also possible to use clay barriers for this purpose in new construction (Geyer [10]). These systems ideally intended to address vapour intrusion that would otherwise enter the workplace to the perimeter of the building footprint or up and out vent piping. They are also used in the construction of SMD systems for the mitigation of crawl spaces and other low traffic areas. As sealing the building envelope system, passive barriers are generally not acceptable as a stand-alone mitigation measure for vapour intrusion, but they serve as a supplemental safety feature for both active and passive systems. Even small imperfections in the barrier (e.g., due to holes, tears, incomplete seals at the footings or pipe penetrations) may produce a significant migration route for soil gas when buildings are depressurized. There are no standard criteria for minimum barrier thickness or physical properties (e.g. elasticity, adherence, compressibility, recovery after stretching and resistance to puncture and tear strength). It has been demonstrated that sheet membranes should have a thickness of at least 1-1.5 mm (USEPA [3]). Using a thicker sheet, 1.5-2.5 mm, (ITRC [1]) may reduce the probability of punctures during activities. For spray-applied or fluid membranes a minimum thickness (e.g. $1.5 \mathrm{~mm}$ ) is recommended. These thicknesses may not even be adequate if the membrane will be heavily burdened by traffic. 


\subsubsection{Passive venting systems}

Passive venting systems consist of different solutions using natural diffusion gradients (resulting from the build-up of soil gas below the building) or pressure (thermal or wind-induced) gradients. Passive vents should be combined with passive barriers. It may be possible to rely on wind-driven ventilation to enhance passive venting, mainly in areas where relatively sustained winds are common.

\subsubsection{Passive sub slab ventilation}

The Passive sub-slab ventilation (SSV) and passive crawlspace ventilation consist of one or more vent pipes installed (placing a vapour barrier) through the slab. These techniques rely on convective flow air upward in the vent pipe to draw air from beneath the slab. This system mitigates the vapour intrusion pathway by intercepting sub-slab soil gas, with a series of appropriately-sized perforated pipes embedded in permeable venting material (gravel, sand, etc.) below the slab, that then discharge to the atmosphere. Perforated pipes are typically placed at the periphery or through the venting media to collect soil gas and convey it to an exhaust point outside the building. Note that perforated pipes are usually not necessary in the venting layer when active systems are installed. Some passive ventilation systems incorporate a wind-driven turbine on the top of the stack to depressurize the pipe and the venting layer. Consider that wind-driven turbines should be used with caution. Turbines do not induce the flow if the wind is not blowing, and may stop the flow of soil gas outwards when ice or snow blocks the turbine. Other passive systems use a heater on the top of the pipe to generate the flow. Passive sub-slab systems are relatively easy to convert to active SSD/SSV systems if needed. These systems are used for new constructions, when total slab replacement is required, in residential and commercial buildings. Some studies by USEPA [2] have shown that, if installation of venting media and passive barriers is not practicable (e.g. in some existing buildings), only low mitigation in vapour intrusion concentrations $(30 \%-70 \%)$ are expected with passive venting systems.

\subsubsection{Measures to increase natural ventilation}

This system consists in opening windows, doors, and vents within a workplace to allow natural ventilation to occur. Increasing ventilation the outdoor air mixes with the indoor contaminated air so reducing indoor levels of the contaminants. The room ventilation rate is inversely proportional to the indoor air concentration: doubling the ventilation rate halves the indoor air concentration. Anyway increasing ventilation in an upper story above the neutral pressure plane may intensify the "stack effect" (due to building heating and mechanical ventilation) causing the inflow of soil gas and therefore being counterproductive. This technique is quick and with no installation cost but for cold climates the cost of heat will eventually make it an expensive mitigation strategy. As an alternative to it crawl space (or basement) ventilation can be implemented. This system applies to crawlspaces substantially enclosed and to foundations without effective cross ventilation (i.e. piers on only one side). This system is preferable in warm climates and where freezing of pipes in the crawl space is not a concern. Consider also that basement venting that causes depressurization is not 
recommended because it may raise contaminants concentrations. Building orientation with regard to prevailing winds can also have an impact on ventilation systems (Geyer [10]). Some studies by Babyak and Welt [11] demonstrated that increasing ventilation does not cause a permanent reduction of contaminants once windows, doors or vents have been closed. For this reason ventilation should only be considered as a temporary measure to reduce concentrations of contaminants in indoor air while other mitigation activities are in progress.

\subsubsection{Modify foundation features}

For existing buildings modifying foundation features may be convenient to provide vapour intrusion mitigation. In some cases perimeter drainage systems can be adopted to provide ventilation under the slab. Ventilation in foundation wall cavities may also be enhanced to reduce contaminants intrusion (USEPA [12]). When one or more ventilation techniques are used, they affect the general balance of air flow within the building. The effects of induced ventilation changes should be carefully evaluated in any workplace with combustion appliances such as heating, drying and/or cooking systems.

\subsection{Alternative mitigation approaches}

Alternatively to the building control remedies described above (the most commonly implemented) sitewide measures and institutional controls can be adopted. Mitigation approaches that are alternatives to active and passive systems, including monitoring programmes, siting of building, etc. are presented here with the understanding that these approaches may be appropriate in some circumstances.

\subsubsection{Monitoring programs}

Monitoring programs for workplaces may also be considered a collective protective measure. The sampling approach should be adopted to demonstrate effectiveness of active/passive measures. Monitoring may or may not involve the collection of many samples. For example, monitoring of active systems may be limited to periodic readings of the static pressure and flow measurements otherwise in passive systems monitoring is an essential part of the mitigation process. The American Society for Testing and Materials [13] suggests "The monitoring frequency will be a function of the timeframe for possible failure of the engineering control (i.e., more frequent for an active system, less frequent for a passive system) and the relative effect of such a failure on a potential receptor (more frequent for immediate impact, less frequent for a delayed impact). Design specifications may include (1) a monitoring frequency that varies over the operating period of the engineering control or (2) a provision to evaluate and modify the monitoring frequency based on data or information obtained during monitoring and maintenance." 


\subsubsection{Siting of buildings}

Siting of buildings can be one of the most efficient measures to control vapour intrusion potential in workplaces. If land adjacent to an affected building is covered, such as parking lots, the resultant direction of vapour migration should be considered so as to not impact other adjacent structures.

\subsubsection{Selective workplaces allocation}

A selective workplace allocation should be adopted to minimize exposure to contaminants. Vapour intrusion exposure depends on the location within the building. E.g. it may double or triple depending on floor or proximity to ventilation sources. Variability is likely to be higher in structures without HVAC systems. This mitigation approach should be evaluated on a case-by-case basis depending on the work phases.

\subsection{Mitigation procedures}

Examples of mitigation procedures to be considered are reported below. They are substantially good hygiene practices and are not meant to be exhaustive:

- minimize workers' exposure (in terms of time, number of workers, proximity),

- do not smoke, eat or drink in most exposed areas or during remediation activities,

- take a shower at the end of workday.

At locations where extremely high concentrations of combustible contaminants are expected adequate procedures for working in the presence of explosive or flammable substances should be adopted (e.g. explosion-proofed equipment must be used, avoid adopting processes that involve the use of flames, provide anti-electrostatic PPE and firefighting equipment, fire blanket, fire extinguishing, etc.), as generally required by EU OSH directives. In oxygen deficient atmosphere self-contained breathing apparatus or air-line respirators must be used.

\section{Outdoor mitigation systems}

\subsection{Active wet control systems}

Wet dust/odour control systems are used for dust/odour prevention (humidity/moisture content in the material is increased to prevent dust from being airborne) or dust and vapour suppression/capture: humidity/moisture is added to the air to capture dust particles that are already airborne. These systems use spray nozzles to apply water and/or chemicals such as wetting, foaming and binding agents to dust and vapour particles. Nozzles produce drops to collide with dust particles that are already airborne. The moisture weighs the particles down so they are returned to the material source or ground. The material/contaminant will also determine whether chemicals should be added to the water to improve suppression. Consider that too much moisture also means 
mud and potentially dangerous maintenance problems. Beside poor quality water can be very problematic because contaminants can be introduced from water supply increasing nozzle maintenance and shortening service life.

\subsection{Passive covering systems}

Using a plastic sheet for dust control. Contaminated sites should be covered with sealed impermeable plastic sheets (e.g. Low Density Polyethylene, High Density Polyethylene, Polyvinylchloride, Polypropylene) to reduce dust and vapour diffusion (Provincia di Milano [14]).

\subsection{Mitigation procedures}

Mitigation procedures to reduce outdoor inhalation are the same for indoor.

\section{Conclusions}

This paper is intended to assist remedial project managers, on-scene coordinators, safety and site managers of remediation activities at contaminated sites. Italian Workers' Safety Laws (Decree no. 81/2008) transposing EU OSH Directives [15, 16] provides priority of collective protective measures over individual ones (PPE). Consequently this review provides an overview of the main collective protective measures for workers in contaminated sites. It is a part of the "Guideline on chemical risk for workers in contaminated sites" developed by a multidisciplinary team of Italian Workers' Compensation Authority in conjunction with Italian Health Ministry, Ministry of Labour and Welfare, Ministry for Environment, Italian National Institute of Health, Venice Local Health Unit and Universities of Rome and of Modena. Mitigation measures and technologies represent in fact effective ways to manage the risk of workers' exposure to pollutants from contaminated soil without stopping work activities in the meanwhile the remediation is in progress or until only industrial activities work on the site.

\section{References}

[1] Vapour Intrusion Pathway: A Practical Guideline, Interstate Technology \& Regulatory Council (ITRC), Vapour Intrusion Team, www.itrcweb.org.

[2] Radon Reduction Techniques for Existing Detached Houses, Technical Guidance for Active Soil Depressurization Systems, United States Environmental Protection Agency (USEPA), http://www.epa.gov/nscep/ index.html

[3] United States Environmental Protection Agency (USEPA), Engineering issues: Indoor Air Vapour Intrusion Mitigation Approaches, Cincinnati (OH), 2008. 
[4] EPA Reducing Radon in Schools: A Team Approach, United States Environmental Protection Agency (USEPA), http://www.epa.gov/ radon/pubs/

[5] Vapour intrusion technical guidance, New Jersey Department of Environmental Protection (NJDEP), Department/Stakeholder Vapour Intrusion Guidance Committee and Department Vapour Intrusion Committee, http://www.nj.gov/dep/srp/guidance/vaporintrusion/vig_main.pdf

[6] Construction Industry Research \& Information Association (CIRIA), The Environmental Handbook for Building and Civil Engineering Projects, Ed. Thomas Telford, USA, 1994.

[7] Interim Final Vapour Intrusion Guidance, Massachusetts Department of Environmental Protection (MassDEP), WSC\#-11-435 online, http://www.mass.gov/eea/agencies/massdep/cleanup/regulations/sit e-cleanup-policies-guidance.html

[8] Vapour Intrusion Mitigation Advisory, Final Revision 1, California Environmental Protection Agency (CalEPA), Department of Toxic Substances Control, https://dtsc.ca.gov/SiteCleanup/.

[9] Final Guidance for the Evaluation and Mitigation of Subsurface Vapour Intrusion to Indoor Air (Vapour Intrusion Guidance), California Environmental Protection Agency (CalEPA), Department of Toxic Substances Control, https://dtsc.ca.gov/SiteCleanup/

[10] Geyer M., Engineering Controls of Vapour Intrusion, Association for Environmental Health \& Sciences (AEHS) West Coast $16^{\text {th }}$ annual Conference, San Diego (CA), March 15, 2006.

[11] Babyak A., Welt S., Vapour Intrusion Mitigation Engineering Controls: Comparison of Methods, Costs and Implementation, Association for Environmental Health \& Sciences (AEHS) West Coast $16^{\text {th }}$ annual Conference, San Diego (CA), March 15, 2006.

[12] Air/Superfund National Technical Guidance, Study Series: Options for Developing and Evaluating Mitigation Strategies for Indoor Air Impacts at CERCLA Sites, United States Environmental Protection Agency (USEPA), EP-451/R-93-012 online, https://www.clu-in.org/conf/tio/vapor 021203/pb94110517.pdf

[13] American Society for Testing and Materials (ASTM), ASTM standard E2435 - 05 Standard Guide for Application of Engineering Controls to Facilitate Use or Redevelopment of Chemical-Affected Properties, Volume: 11.05, Ed. ASTM International, PA, 2010.

[14] Linee Guida per la verifica ed il collaudo delle barriere impermeabili per la messa in sicurezza di siti contaminati, Provincia di Milano e Università degli Studi di Milano, http://www.provincia.milano.it/export/sites/default/ ambiente/doc/p_bonifiche_lineeguida04_barriere_impermeabili.pdf

[15] Council Directive $89 / 39 \overline{1} / \mathrm{EEC}$ on the introduction of measures to encourage improvements in the safety and health of workers at work - "Framework Directive", European Parliament and Council, 
http://eur-lex.europa.eu/LexUriServ/LexUriServ.do?uri=CELEX:31989L0 391:en:HTML

[16] Communication from the Commission to the European parliament, the Council, the European economic and social committee and the committee of regions on the practical implementation of the provisions of the health and safety at work Directives 89/391 (Framework), 89/654 (Workplaces), 89/655 (Work Equipment), 89/656 (Personal Protective Equipment), 90/269 (Manual Handling of Loads) and 90/270 (Display Screen Equipment), European Parliament and Council, Brussels, 2004, http://eurlex.europa.eu/LexUriServ/ 